\title{
Intrastromal Corneal Ring Segments for Astigmatism Correction after Deep Anterior Lamellar Keratoplasty
}

\author{
Júlio C. D. Arantes, ${ }^{1}$ Sandro Coscarelli, ${ }^{2}$ Paulo Ferrara, ${ }^{3}$ Luana P. N. Araújo, ${ }^{4}$ \\ Marcos Ávila, ${ }^{1}$ and Leonardo Torquetti ${ }^{5}$ \\ ${ }^{1}$ Center of Reference in Ophthalmology, Federal University of Goiás, Goiânia, Brazil \\ ${ }^{2}$ Ennio Coscarelli Eye Clinic, Belo Horizonte, Brazil \\ ${ }^{3}$ Paulo Ferrara Eye Clinic, Belo Horizonte, Brazil \\ ${ }^{4}$ Altino Ventura Foundation, Recife, Brazil \\ ${ }^{5}$ Center of Excellence in Ophthalmology, Pará de Minas, Brazil
}

Correspondence should be addressed to Júlio C. D. Arantes; juliocdaher@gmail.com

Received 13 March 2017; Accepted 17 July 2017; Published 29 August 2017

Academic Editor: Daniel Gore

Copyright ( 2017 Júlio C. D. Arantes et al. This is an open access article distributed under the Creative Commons Attribution License, which permits unrestricted use, distribution, and reproduction in any medium, provided the original work is properly cited.

\begin{abstract}
Background. To evaluate the change in corneal astigmatism after intrastromal corneal ring segment (ICRS) implantation in keratoconus patients with previous deep anterior lamellar keratoplasty (DALK). Design was a longitudinal, retrospective, interventional study. The study included 25 eyes of 24 patients with keratoconus who had DALK performed at least two years prior to ICRS implantation. All patients had a clear corneal graft with up to $8.00 \mathrm{D}$ of corneal astigmatism and intolerance to contact lenses. The studied parameters were age, sex, corrected distance visual acuity (CDVA), maximum keratometry (K1), minimum keratometry (K2), spherical equivalent, and astigmatism. There was a statistically significant decrease in the postintervention analysis as follows: $3.5 \mathrm{D}$ reduction in $\mathrm{K} 1(p<0.001)$; $1.53 \mathrm{D}$ in $\mathrm{K} 2(p=0.005)$; and $2.52 \mathrm{D}(p<0.001)$ in the average $K$. The spherical equivalent reduced from $-3.67 \mathrm{D}( \pm 2.74)$ to $-0.71 \mathrm{D}( \pm 2.35)(p<0.001)$. The topographic astigmatism reduced from $3.87 \mathrm{D}$ preoperatively to $1.90 \mathrm{D}$ postoperatively $(p<0.001)$. The CDVA improved from $0.33( \pm 0.10)$ to 0.20 $( \pm 0.09, p<0.001)$. ICRS implantation is a useful option for the correction of astigmatism after DALK as it yields significant visual, topographic, and refractive results.
\end{abstract}

\section{Introduction}

Keratoconus is a noninflammatory, progressive ectatic disease characterized by thinning and protrusion of the cornea. It causes progressive myopia and irregular astigmatism, decreasing the quality of vision [1].

Treatment of keratoconus is indicated according to disease severity. Initially, correction is achieved by wearing glasses, followed by the fitting of rigid gas permeable contact lenses (RGPCL). When these methods fail, surgery is indicated to improve the corneal surface. [2]. When the cornea still appears transparent, the implantation of intrastromal corneal ring segments (ICRS) may be a successful option, and in many cases, it represents an alternative to corneal transplantation [3-6].
Penetrating keratoplasty (PKP) used to be the method of choice for treating ectatic corneal disease and has been the standard procedure for the keratoconus patient. A disadvantage of this method is its greater potential for graft rejection, which can lead to a significant reduction in visual acuity. [7-10]. The alternative approach has been deep anterior lamellar keratoplasty (DALK), in which a splitthickness graft is sutured to the receptor, sparing the host's endothelium and Descemet's membrane and avoiding the risk of endothelial rejection, with similar visual results [9]. DALK can be used in virtually all cases of corneal opacity not involving the endothelium, and it proved to be a valuable alternative to PKP for treating keratoconus [10-13].

The surgical duration and risk of ocular perforation have decreased, and the technique [11] has also provided an 
optical surface of excellent quality. In cases of a high residual post-DALK astigmatism, one alternative is intrastromal corneal ring segment (ICRS) implantation, which may be indicated for transparent corneas. [14, 15] The main goal is to reshape the cornea without removing tissue or weakening its central or paracentral region [16].

This study evaluated the use of intrastromal corneal ring segments implanted using a femtosecond laser as a surgical option for treating patients undergoing DALK due to keratoconus. No other studies were found that have evaluated the results of employing this implant in the same manner as proposed here.

\section{Methodology}

This was a retrospective, longitudinal study with secondary data collected from the medical records of patients diagnosed with keratoconus who underwent intrastromal corneal ring implantation for residual astigmatism correction after DALK.

An informed consent was given to all eligible patients prior to data collection, requesting permission for the research and use of data from their medical records relating to the pre- and postoperative periods. All bioethical principles were considered in accordance with the Declaration of Helsinki and Brazilian regulations.

The following were considered inclusion criteria: a clear and transparent corneal graft, a minimum of 2.50 diopters (D) and a maximum of $8.00 \mathrm{D}$ of astigmatism, intolerance to contact lenses, and at least two years of follow-up after DALK before implanting the intrastromal corneal ring. Exclusion criteria were age under 18 years, having undergone DALK to treat a disorder other than keratoconus, any ocular surgery other than those proposed in the present study, history of corneal graft rejection, and any other associated ocular disease.

To evaluate the preoperative parameters, the data used were taken from the information recorded on the last visit prior to when surgery was indicated. All patients had completed at least one year of follow-up after ICRS implantation, and the second evaluation was based on information taken after this period had elapsed. Clinical variables were corrected distance visual acuity (CDVA), measured with the patient at a distance of 6 meters from the Snellen table, without cycloplegy. To analyze CDVA, the Snellen fractions were converted to LogMAR. Maximum keratometry (K1) and minimum keratometry (K2) were measured in diopters, using EyeSys topography (EyeSys Vision, Houston, United States). The spherical equivalent, in cylindrical diopters (DC), was obtained during refractometry performed with the patient at a distance of 6 meters from the Snellen table, without cycloplegy. Topographic astigmatism was measured in diopters, using EyeSys topography (EyeSys Vision, Houston, United States).

All ICRS implantations were performed by the same surgeon (SC). The procedures were performed from June 2012 to September 2013. These interventions were made using a standard technique, as previously describe [17].

DALK surgery was performed under peribulbar anesthesia. The cornea was partially trephined at a diameter of
$7.5 \mathrm{~mm}$. A radial incision was made with a diamond blade at the $90^{\circ}$ meridian, which reached $90 \%$ of the corneal depth, from which stromal tunnels were created using a spatula. Air was injected into the stromal tunnels to create a deep cleavage between Descemet's membrane and the posterior stroma. Atraumatic Vannas scissors were used to remove the anterior stromal tissue along the edge of the existing partial trepanation. The donor cornea was trephined with a diameter $0.25 \mathrm{~mm}$ greater than that used in the recipient. The endothelium of the graft was completely removed. The donor button was fixed with 16 separate sutures using mononylon 10.0. Postoperatively, $0.3 \%$ moxifloxacin eye drops combined with $0.1 \%$ dexamethasone, four times a day for a period of six weeks, were prescribed. Lubricant eye drops were used several times a day, according to each patient's needs. The sutures removal began three months after surgery.

The ICRS surgical implantation procedure was performed under topical anesthesia. The Purkinje reflex was chosen and marked with the tip of a Sinskey hook. A $5 \mathrm{~mm}$ corneal marker was used to locate the exact area of the channel for the ICRS implant. The depth of the tunnel was set at $75 \%$ of corneal thickness at its thinnest area. An incision was made on the steepest topographic axis, with one or two segments implanted according to the distribution of the ectatic area on the corneal surface and the degree of topographic astigmatism. A femtosecond laser frequency of $60 \mathrm{kHz}$ (LDV Z6, Ziemer, Switzerland) was used to create the ring segment tunnels. Special attention was given to centralizing the suction ring to mark the center point to minimize decentration. The inner diameter of the channel was set at $4.4 \mathrm{~mm}$, and the outer diameter was $5.6 \mathrm{~mm}$; the energy used to create the channel was $1.30 \mathrm{~J}$. The time taken to create the channel with the femtosecond laser was seconds. The ICRS were implanted immediately after creation of the channel (before the disappearance of the bubbles) and were inserted using a modified McPherson forceps. The segments were correctly positioned with the aid of a Sinskey hook. Postoperative procedures included the application of $0.3 \%$ moxifloxacin eye drops combined with $0.1 \%$ dexamethasone, four times daily for two weeks. Furthermore, patients received topical lubricants to be applied four times a day for at least three months (Figure 1).

All patients were evaluated within the service's routine, which offered return visits on the first and seventh postoperative day, after one and six months, and annually thereafter; for analysis purposes, the postoperative data were considered after one year of follow-up.

Data were analyzed using the Statistical Package for the Social Sciences (SPSS), version 19.0. The KolmogorovSmirnov test was applied to identify the distribution of continuous variables, and Student's t-test, the Welch transformation, and the nonparametric Mann-Whitney tests were also applied. All tests considered a significance level of $5 \%$ and a $95 \%$ confidence interval.

\section{Results}

This study included 25 eyes of 24 patients, 14 patients were male $(58.33 \%)$ and 10 were female (41.66\%), aged $20-54$ 


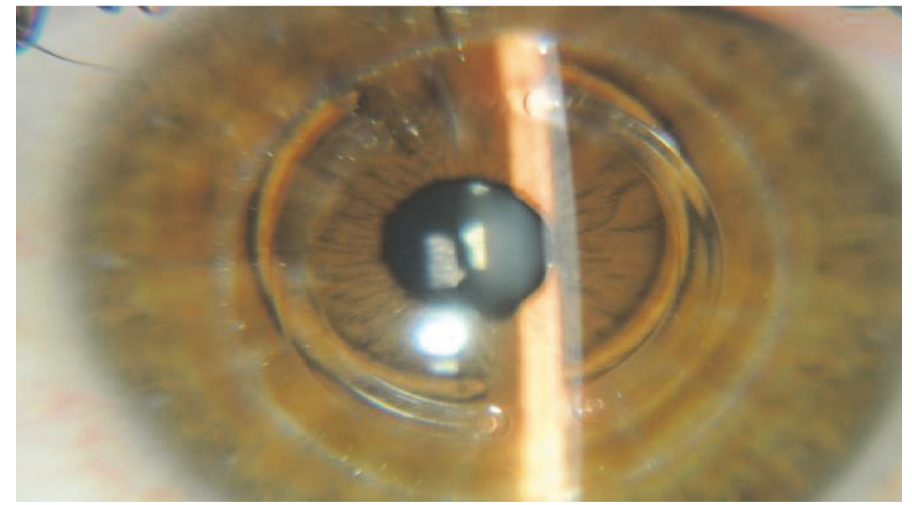

FIGURE 1: Transparent cornea one week after the ICRS implant.
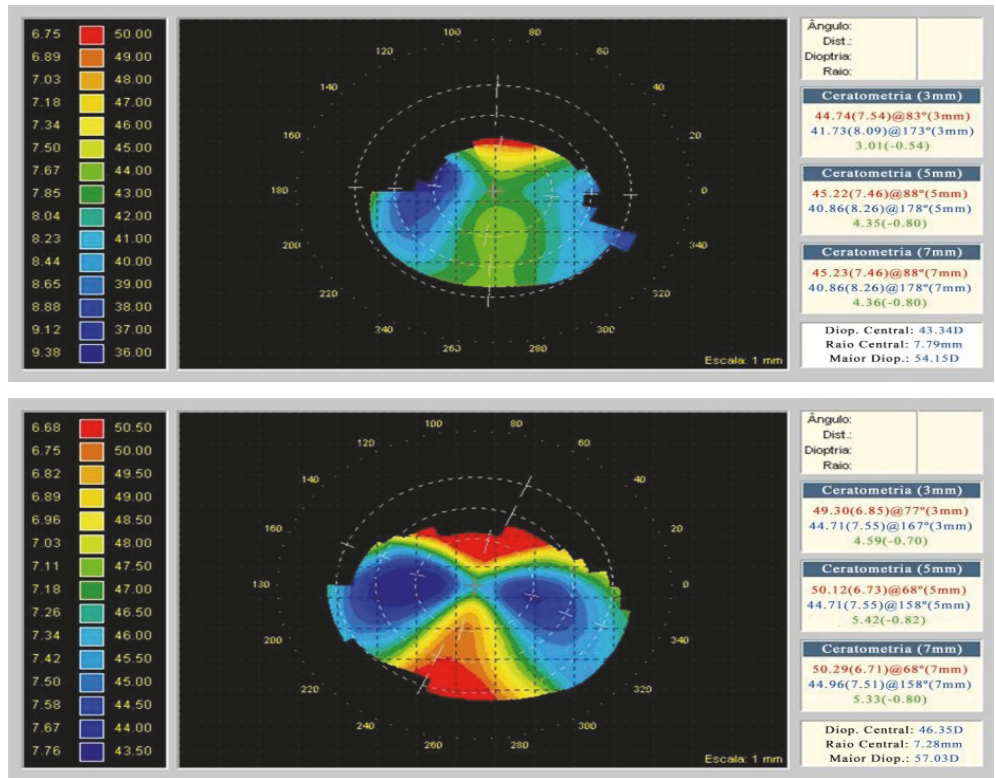

FIGURE 2: Preoperative and postoperative corneal topography after ICRS implantation.

years (mean: 35.96; standard deviation: \pm 8.69 years). The indication for ring implantation was to correct residual astigmatism after DALK. Twenty-three patients had one eye treated, and only one patient had both eyes treated.

All clinical variables showed a statistically significant decrease from preoperative to postoperative. There was a reduction of $3.50 \mathrm{D}$ in $\mathrm{K} 1 \quad(p<0.001)$ and $1.53 \mathrm{D}$ in $\mathrm{K} 2(p=0,005)$, and the reduction in the mean $K$ was 2 . D $(p<0.001)$ (Figure 2).

The spherical equivalent (SE) reduced from $-3.67 \mathrm{D}$ $( \pm 2.74)$ before the procedure to $-0.71 \mathrm{D}( \pm 2.35)$ after the procedure $(p<0.001)$. Topographic astigmatism reduced from $3.87 \mathrm{D}$ preoperatively to $1.90 \mathrm{DC}$ postoperatively $(p<0.001)$ (Table 1$)$. The corrected distance visual acuity (CDVA), in LogMAR, increased from $0.33( \pm 0.10)$ to 0.20 $( \pm 0.09 ; p<0.001)$.

Vector analysis (double-angle plot) revealed a significant decrease in the centroid between the preoperative and postoperative data in both topographic astigmatism and refractive astigmatism (Figure 3 ).
TABle 1: Preoperative and postoperative data after ICRS implantation.

\begin{tabular}{|c|c|c|c|c|c|}
\hline & \multicolumn{2}{|c|}{ Preop } & \multicolumn{2}{|c|}{ Postop } & \multirow{2}{*}{$p^{*}$} \\
\hline & Mean & SD & Mean & SD & \\
\hline Maximum keratometry & 47.20 & \pm 2.50 & 43.70 & \pm 3.45 & $<0.001$ \\
\hline Minimum keratometry & 43.33 & \pm 2.00 & 41.80 & \pm 3.53 & 0.005 \\
\hline Mean keratometry & 45.26 & \pm 2.03 & 42.74 & \pm 3.44 & $<0.001$ \\
\hline Spherical equivalent & -3.67 & \pm 2.74 & -0.71 & \pm 2.35 & $<0.001$ \\
\hline Topographic astigmatism & 3.87 & \pm 1.95 & 1.90 & \pm 1.16 & $<0.001$ \\
\hline
\end{tabular}

*Student's $t$-test for paired samples, $p$ value. SD: standard deviation.

The preoperative refractive astigmatism centroid was $1.87 \mathrm{D} \times 4.66^{\circ} \pm 3.76(p=1.55)$, and the postoperative centroid was $1.01 \mathrm{D} \times 21.31^{\circ} \pm 1.84(p=0.83)$. After implantation of the ICRS, the refractive astigmatism centroid was $0.86 \mathrm{D}$, and the standard deviation in astigmatism was reduced by a 


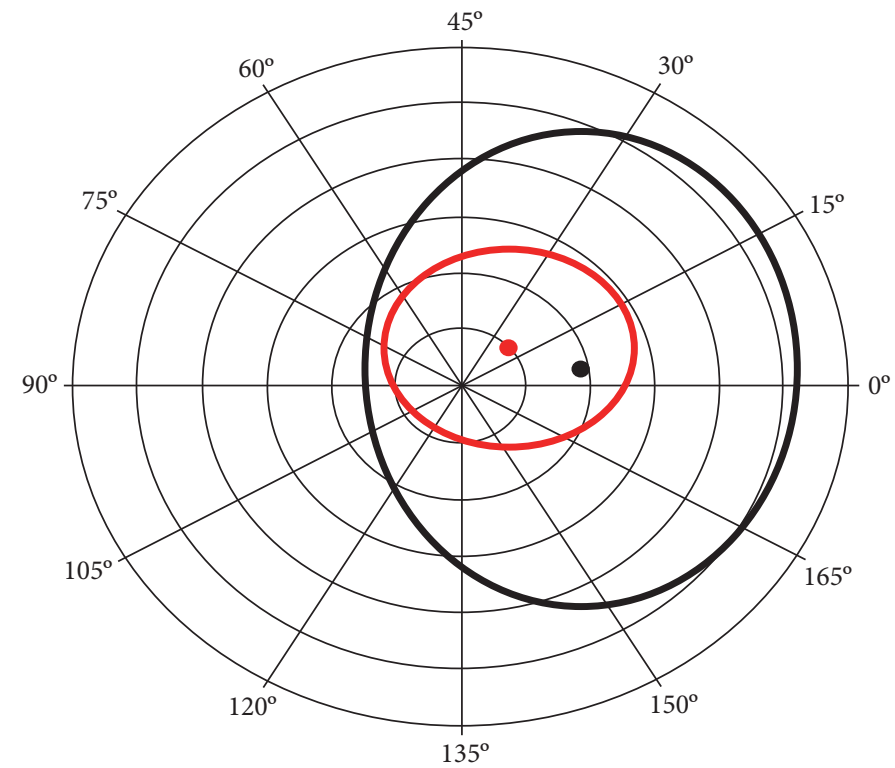

Each ring $=1.0 \mathrm{D}$

Outer ring $=6.0 \mathrm{D}$

Preoperative centroid: $1.87 \mathrm{D} \times 4.66^{\circ} \pm 3.76, p=1.55$

Postoperative centroid: $1.01 \mathrm{D} \times 21.31^{\circ} \pm 1.84, p=0.83$

Figure 3: Double-angle plot of preoperative and postoperative refractive astigmatism. The standard deviation is represented by the area around the centroid ( $p=$ shape factor). Each ring $=1.0 \mathrm{D} /$ outer ring $=6.0 \mathrm{D}$.

factor of $1.92(3.76 \mathrm{D} / 1.84 \mathrm{D})$. Relocation of the centroid nearer to the origin and contraction of the ellipse in the double-angle plots showed improvement (Figure 3).

Figure 4 shows the double-angle plot for preoperative and postoperative keratometric astigmatism. The preoperative centroid was $0.97 \mathrm{D} \times 91.97^{\circ} \pm 1.74,(p=0.95)$, and the postoperative centroid was $0.75 \mathrm{D} \times 98.59^{\circ} \pm 1.50,(p=0.82)$. Although there was a reduction in mean keratometric astigmatism, it was considerably smaller than the decrease in refractive astigmatism.

\section{Discussion}

The most common cause of decreased vision after corneal transplantation is the astigmatism. It is commonly accepted that the average postoperative cylinder after keratoplasty varies from three to five diopters; [18] about $10-27 \%$ of patients undergoing corneal transplantation evolve with high astigmatism, and for high astigmatism, it is understood as the refractive cylinder of more than four diopters (D) [19].

In the present study, using ICRS implantation to treat high astigmatism after the DALK significantly reduced $K$ values, spherical equivalent, and the topographic astigmatism. Tunnels made with the femtosecond laser have an advantage over those implanted using the manual technique because they cause lower traction at the junction where the recipient cornea meets the donor button, avoiding possible dehiscence in the surgical wound [3] (Figure 5).

The choice of a Ferrara ICRS with a $5 \mathrm{~mm}$ optical zone also has advantages over choosing those that are implanted in a 6 or $7 \mathrm{~mm}$ optic zone, as the former theoretically causes greater corneal flattening because the refractive results are inversely proportional to the implant diameter [16]. Furthermore, a smaller optical zone provides greater distance between the ICRS and graft/host junction, reducing the chance of stromal neovascularization/dehiscence of the junction. In turn, a smaller optical zone increases the risk of postoperative halos. Excimer laser photorefractive keratectomy (PRK) and laser in situ keratomileusis (LASIK) can also be used to treat posttransplant astigmatism [20].

The fact that the ICRS implant did not affect the central region of the cornea, avoiding the risk of opacity on the visual axis and the reversibility of this method, means that this can be considered theoretically more beneficial than the correction of astigmatism using LASIK, which has limited efficacy due to the stromal thickness of the graft and the high remaining ametropia [20].It also does not provide results as good as those seen in corneas that have never been treated, with less predictability and greater chance of complications such as epithelialization defects, flap displacement, dry eye, and corneal graft failure $[18,21,22]$. PRK can cause a significant haze in corneal grafts and induce progressive astigmatism [20].

Another surgical option for the treatment of post-DALK astigmatism is the implantation of a phakic intraocular lens (PIOL). Barraquer and Rodriguez-Barraquer [23] evaluated the Artisan PIOL implant in the treatment of high myopia after PKP. In that study, there was an improvement in CDVA without significant loss of endothelial cells in the first six postoperative months [23]. 


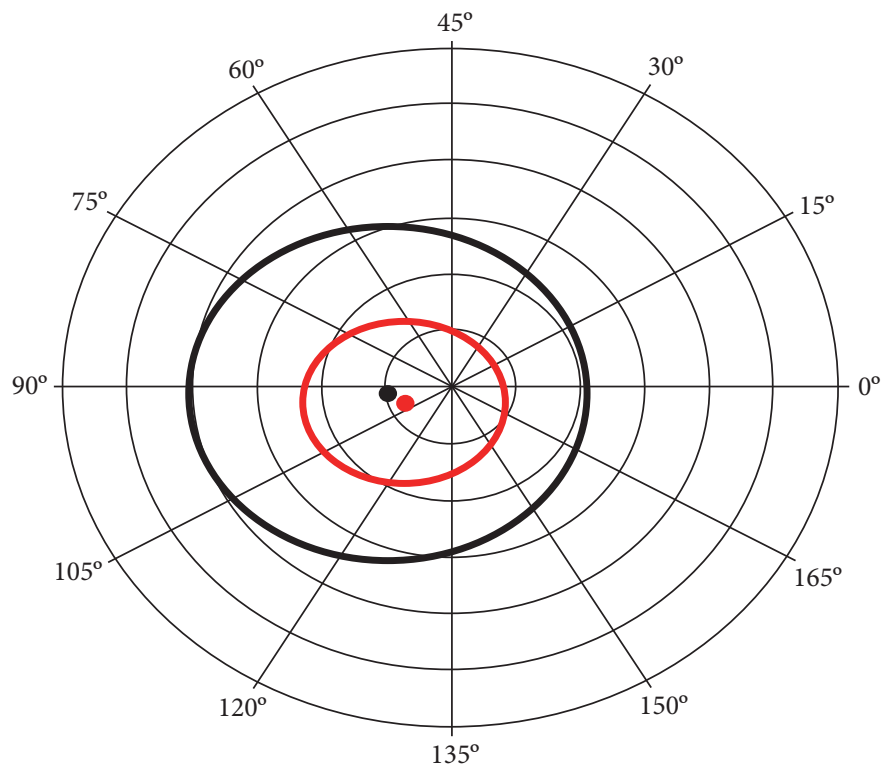

Each ring $=1.0 \mathrm{D}$

Outer ring $=6.0 \mathrm{D}$

Preoperative centroid: $0.97 \mathrm{D} \times 91.97^{\circ} \pm 1.74, p=0.95$

Postoperative centroid: $0.75 \mathrm{D} \times 98.59^{\circ} \pm 1.50, p=0.82$

FIGURE 4: Relationship between preoperative and postoperative keratometric astigmatism. The standard deviation is represented by the area around the centroid ( $p=$ shape factor). Each ring $=1.0 \mathrm{D} /$ outer ring $=6.0 \mathrm{D}$.

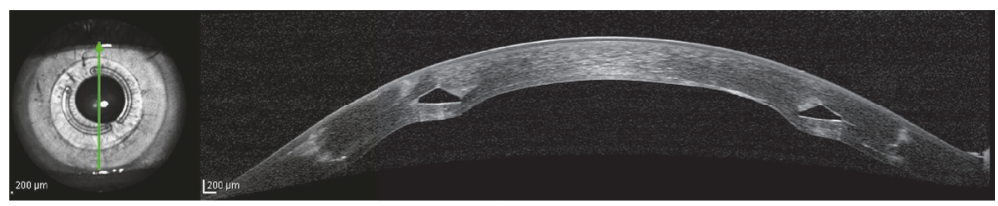

FIGURE 5: Optical coherence tomography (OCT) of the cornea one year after the procedure, showing the position of the ICRS.

Another study demonstrated that a PIOL implant in post-PKP eyes reduces refractive error and improves the CDVA, in addition to being a predictable and stable method. However, even if the refractive error is significantly reduced, corneal abnormalities will still be present. Alternatively, an ICRS implant decreases these abnormalities, improving the quality of vision. In addition, as it is a less invasive corneal procedure, the risks related to intraocular surgery are avoided [24]. Alfonso et al. [25] evaluated the efficacy and safety of the implantable collamer posterior chamber intraocular lenses to correct refractive errors that occurred after PKP in 15 eyes of 15 patients. In this study, no eye lost more than one line of vision, two eyes gained one line, five eyes gained more than one line, and eight eyes remained with unchanged vision $[25,26]$.

In the current study, when evaluating the CDVA 12 months after ICRS implantation, stability was observed in $28 \%$ (seven eyes); $36 \%$ (nine eyes) gained one line of vision; $20 \%$ (five eyes) gained two lines of vision; $8 \%$ (two eyes) gained three lines of vision; and 8\% (two eyes) gained four lines of vision. No eyes lost lines of vision.
Other scientific studies using a post-PKP manual intrastromal corneal ring implant technique showed $K$ reduction values higher than those found in our study. A study conducted in Spain, with the participation of nine patients (nine eyes), found a reduction in $\mathrm{K} 1$ values greater than $5 \mathrm{D}$ and a reduction in $\mathrm{K} 2$ greater than $2 \mathrm{D}$, while the mean $K$ decreased by more than $4 \mathrm{D}$ [3]. In another publication using a similar technique conducted in Brazil evaluating patients (59 eyes), $K$ values were also reduced by more than the amount found in our study, with the maximum $K$ decreasing by $3.92 \mathrm{D}$ and the minimum $K$ by $2.44 \mathrm{D}$ [17].

In another study with 30 patients (32 eyes) using a femtosecond laser for post-PKP intrastromal corneal ring implantation, lower reductions in K2 $(0.53 \mathrm{D})$ and $\mathrm{K} 1$ (3.65 D) were found, a result similar to that of our study [14].

Arriola-Villalobos [27] found that the spherical equivalent decreased by $3.05 \mathrm{D}$, and Coscarelli et al. [16] reported a decrease of $3.68 \mathrm{D}$. These values are similar to those found in our study, in which we observed a decrease of $2.96 \mathrm{D}$. In the study of Lisa et al. [13], a smaller reduction in the spherical equivalent of 1.67 D was observed. 
Topographic astigmatism decreased 1.97 in our study, whereas in another similar study, a decrease of 2.59 was obtained [9].

We hypothesize that the results, in terms of reduction of keratometry and astigmatism, are less significant in cases of ICRS implantation after DALK, in comparison of ICRS after PKP due to biomechanics properties of the cornea The preservation of Descemet's membrane and endothelium in DALK provides an additional strength to the graft, comparing to PKP, which in turns, leads to less response to corneal flattening/remodeling after ICRS implantation in these cases. Moreover, the irregularity at host-donor interface may play a role in the corneal changes after ICRS implantation after PKP.

In our investigation, there were no complications during the surgery or postoperative follow-up. The use of the femtosecond laser in the construction of stromal tunnels is safer than the manual technique, providing a significant reduction in complications such as ICRS extrusion because of the accuracy in implant depth [27-29].

One limitation of the study was the lack of standardization in the medical records, making the data difficult to collect and increasing the time required to populate the database, although all the information necessary for the proposed evaluations were obtained in the documents.

One of the strengths of this study is the fact that no other studies were found that evaluates the results of ICRS implantation using a femtosecond laser in patients previously undergoing DALK due to keratoconus. The number of patients selected was lower than ideal due to the rigorous selection of the studied eyes. The strict inclusion and exclusion criteria limited the sample to 25 eyes, but statistical significance was achieved.

The results of this study indicate that ICRS implanted using a femtosecond laser is a surgical treatment option for patients having undergone DALK due to keratoconus that offers significant visual, topographic, and refractive results. Prospective studies with longer follow-up periods are needed to verify the long-term safety and stability of the procedure.

4.1. What Was Known before This Study. The use of a femtosecond laser for intrastromal corneal ring implantation is a safe option for treating astigmatism after PKP.

4.2. What This Study Has Added. This is the first published study of ICRS implantation with a femtosecond laser to correct high astigmatism in eyes that were previously subjected to DALK due to keratoconus.

In a series of 25 eyes, the ICRS implant produced a significant reduction in topographic astigmatism and improved the CDVA in patients previously undergoing deep anterior lamellar keratoplasty.

\section{Synopsis}

ICRS implantation can successfully improve the visual acuity and reduce the astigmatism after deep anterior lamellar keratoplasty.

\section{Disclosure}

Ferrara has financial interest in Ferrara intrastromal cornea ring segments. No other author has a financial or proprietary interest in any material or method mentioned.

\section{Conflicts of Interest}

The authors declare that they have no conflicts of interest.

\section{References}

[1] L. S. Lim, R. Beuerman, L. Lim, and D. T. Tan, "Late-onset deep stromal scarring after riboflavin-UV-A corneal collagen cross-linking for mild keratoconus," Archives of Ophthalmology, vol. 129, pp. 360-362, 2011.

[2] Y. S. Rabinowitz, "Keratoconus," Survey of Ophthalmology, vol. 42, pp. 297-319, 1998.

[3] N. Avni-Zauberman and D. S. Rootman, "Cross-linking and intracorneal ring segments-review of the literature," Eye \& Contact Lens, vol. 40, pp. 365-370, 2015.

[4] G. Ferrara, L. Torquetti, P. Ferrara, and J. Merayo-Lloves, "Intrastromal corneal ring segments: visual outcomes from a large case series," Clinical \& Experimental Ophthalmoogy, vol. 40, pp. 433-439, 2012.

[5] L. Torquetti, G. Ferrara, F. Almeida et al., "Intrastromal corneal ring segments implantation in patients with keratoconus: 10-year follow-up," Journal of Refractive Surgery, vol. 30, pp. 22-26, 2014.

[6] J. S. Parker, K. DijkVan, and G. R. Melles, "Treatment options for advanced keratoconus: a review," Survey Ophthalmology, vol. 60, pp. 459-480, 2015.

[7] A. Cano-Ortiz and A. Villarrubia, "Corneal transplantation in keratoconus: penetrating keratoplasty versus deep anterior lamellar keratoplasty with Melles technique," Archivos de la Sociedad Espanola de Oftalmologia, vol. 90, pp. 4-8, 2015.

[8] R. Donoso, C. Díaz, and P. Villavicencio, "Comparative study of keratoconus between Anwar's deep anterior lamellar keratoplasty versus converted penetrating keratoplasty," Archivos de la Sociedad Espanola de Oftalmologia, vol. 90, pp. 257263, 2015.

[9] M. Keane, D. Coster, M. Ziaei, and K. Williams, “Deep anterior lamellar keratoplasty versus penetrating keratoplasty for treating keratoconus," Cochrane Database Systematic Review, vol. 7, article CD009700, 2014.

[10] S. L. Watson, S. J. Tuft, and J. K. Dart, "Patterns of rejection after deep lamellar keratoplasty," Ophthalmology, vol. 113, pp. 556-560, 2006.

[11] M. Anwar and K. D. Teichmann, "Big bubble technique to bare Descemet's membrane in anterior lamellar keratoplasty," Journal of Cataract \& Refractive Surgery, vol. 28, no. 3, pp. 398-403, 2002.

[12] S. Feizi, S. Daryabari, D. Najdi, M. A. Javadi, and F. Karimian, "Big-bubble deep anterior lamellar keratoplasty using central vs peripheral air injection: a clinical trial," European Journal Ophthalmology, vol. 26, no. 4, pp. 297-302, 2016.

[13] C. Lisa, M. García-Fernández, D. Madrid-Costa, L. Torquetti, J. Merayo-Lloves, and J. F. Alfonso, "Femtosecond laserassisted intrastromal corneal ring segment implantation for high astigmatism correction after penetrating keratoplasty," 
Journal of Cataract \& Refractive Surgery, vol. 39, no. 11, pp. 1660-1667, 2013.

[14] J. Colin, C. Buestel, and D. Touboul, "Unusual secondary displacement of Intacs segments-superimposition of distal ends," Journal of Refractive Surgery, vol. 26, no. 12, pp. 924925, 2010.

[15] S. Coscarelli, G. Ferrara, J. F. Alfonso et al., "Intrastromal corneal ring segment implantation to correct astigmatism after penetrating keratoplasty," Journal of Refractive Surgery, vol. 38, no. 6, pp. 1006-1013, 2012.

[16] S. A. Coscarelli, R. C. Neves, and J. E. Boteon, "Deep lamellar keratectomy using the big-bubble technique in patients with keratoconus," Arquivos Brasileiros de Oftalmologia, vol. 75, pp. 20-23, 2012.

[17] S. Coscarelli and L. Torquetti, "Easy bubble: Pachymetryassisted big bubble deep anterior lamellar keratoplasty," Journal of Emmetropia, vol. 3, pp. 151-154, 2012.

[18] A. D. Jensen and A. E. Maumenee, "Refractive errors following keratoplasty," Transactions of the American Ophtalmologic, vol. 72, pp. 123-131, 1974.

[19] G. I. Genvert, E. J. Cohen, J. J. Arentsen, and P. R. Laibson, "Fitting gas-permeable contact lenses after penetrating keratoplasty," American Journal of Ophtalmology, vol. 5, no. 5, pp. 511-514, 1985.

[20] J. I. Barraquer, "Modification of refraction by means of intracorneal inclusions," International Ophthalmology Clinics, vol. 6, pp. 53-78, 1966.

[21] S. Kwitko, D. R. Marinho, S. Rymer, and F. S. Ramos, "Laser in situ keratomileusis after penetrating keratoplasty," Journal of Cataract \& Refractive Surgery, vol. 27, no. 3, pp. 374-379, 2001.

[22] E. D. Donnenfeld, H. S. Kornstein, A. Amin et al., "Laser in situ keratomileusis for correction of myopia and astigmatism after penetrating keratoplasty," Ophthalmology, vol. 106, no. 10, pp. 1966-1974, 1999.

[23] C. Barraquer and T. Rodriguez-Barraquer, "Five-year results of laser in-situ keratomileusis (LASIK) after penetrating keratoplasty," Cornea, vol. 23, no. 3, pp. 243-248, 2004.

[24] M. Moshirfar, C. A. Barsam, and J. W. Parker, "Implantation of an artisan phakic intraocular lens for the correction of high myopia after penetrating keratoplasty," Journal of Cataract \& Refractive Surgery, vol. 30, no. 7, pp. 1578-1581, 2004.

[25] J. F. Alfonso, C. Puchades, L. Fernández-Vega, R. MontésMicó, B. Valcárcel, and T. Ferrer-Blasco, "Visual acuity comparison of 2 models of bifocal aspheric intraocular lenses," Journal of Cataract \& Refractive Surgery, vol. 35, no. 4, pp. 672-676, 2009.

[26] J. F. Alfonso, L. Fernández-Vega, B. Baamonde, D. MadridCosta, and R. Montés-Micó, "Refractive lens exchange with spherical diffractive intraocular lens implantation after hyperopic laser in situ keratomileusis," Journal of Cataract \& Refractive Surgery, vol. 35, no. 10, pp. 1744-1750, 2009.

[27] P. Arriola-Villalobos, D. Díaz-Valle, J. L. Güell et al., "Intrastromal corneal ring segment implantation for high astigmatism after penetrating keratoplasty," Journal of Cataract \& Refractive Surgery, vol. 35, no. 11, pp. 1878-1884, 2009.
[28] D. Ortiz, D. Piñero, M. H. Shabayek, F. Arnalich-Montiel, and J. L. Alió, "Corneal biomechanical properties in normal, post-laser in situ keratomileusis, and keratoconic eyes," Journal of Cataract \& Refractive Surgery, vol. 33, no. 8, pp. 1371-1375, 2007.

[29] A. Ertan and G. Kamburoğlu, "Intacs implantation using a femtosecond laser for management of keratoconus: comparison of 306 cases in different stages," Journal of Cataract \& Refractive Surgery, vol. 34, no. 7, pp. 1521-1526, 2008. 


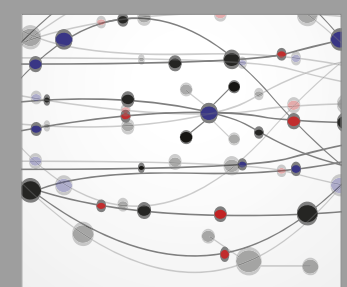

The Scientific World Journal
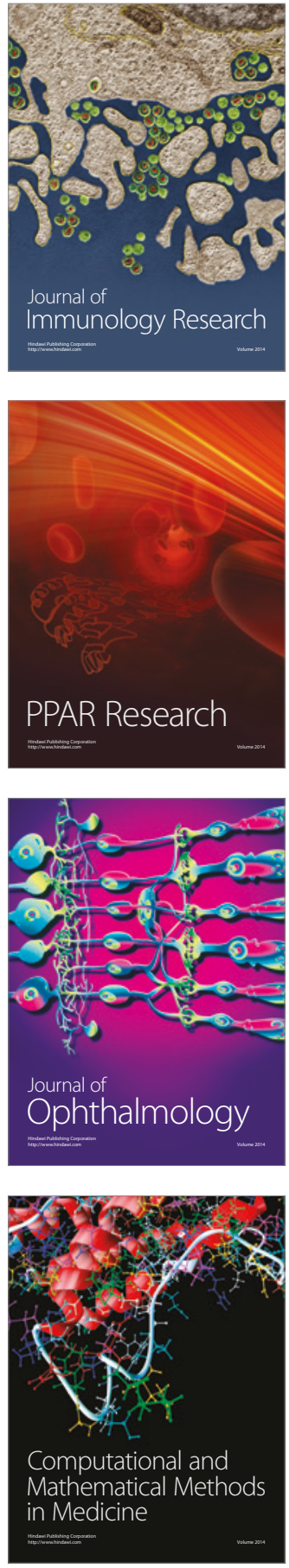

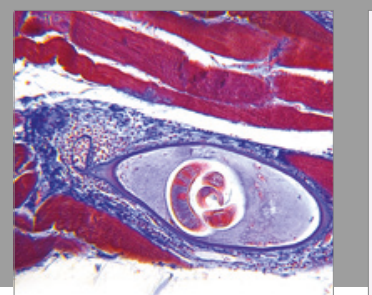

Gastroenterology Research and Practice
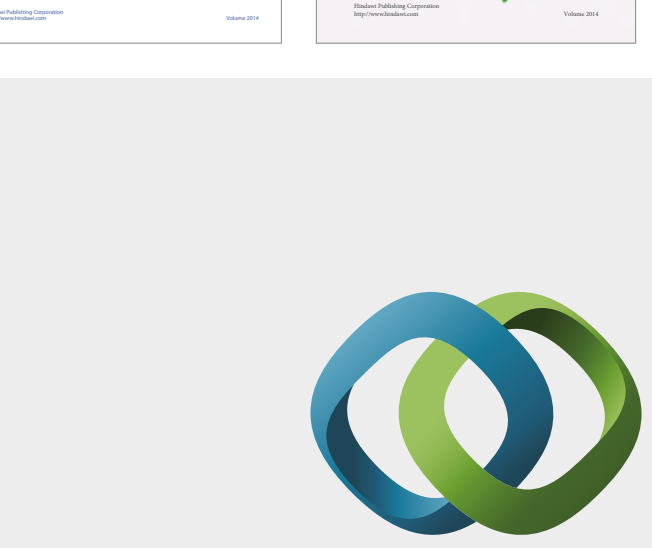

\section{Hindawi}

Submit your manuscripts at

https://www.hindawi.com
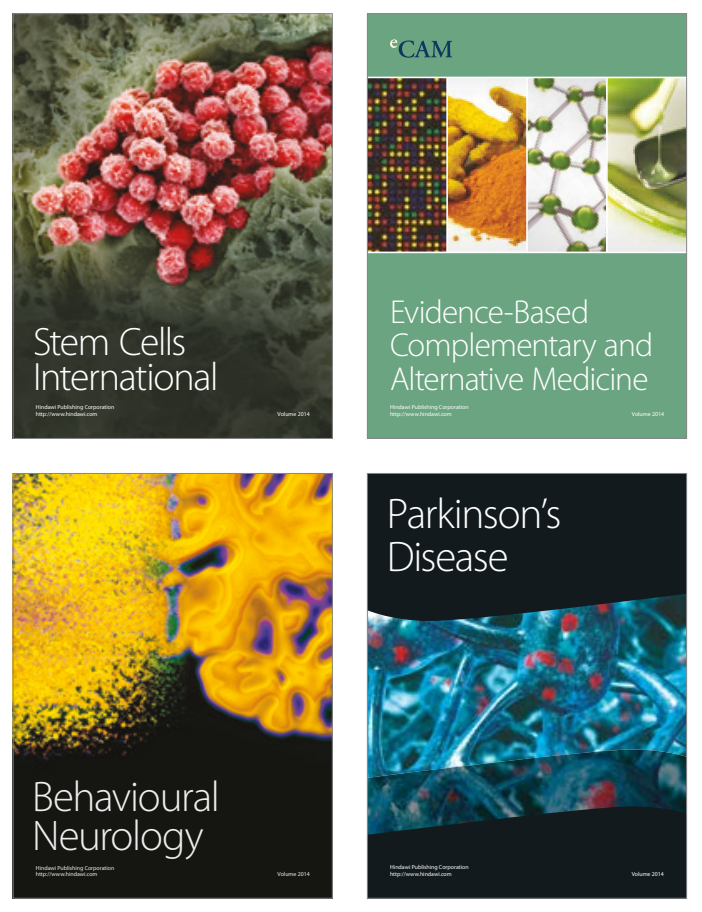
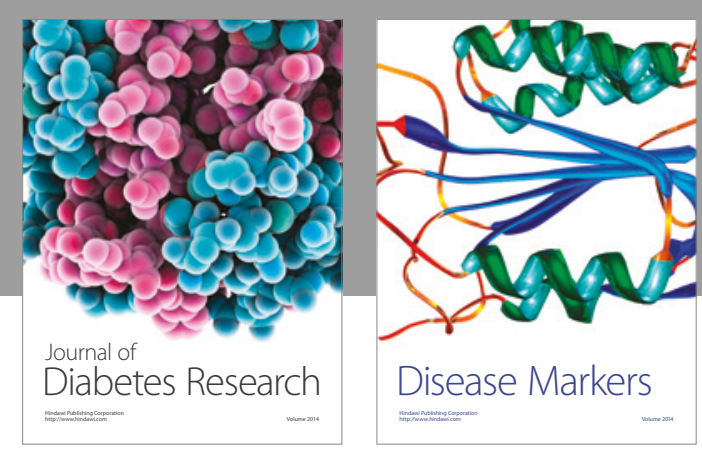

Disease Markers
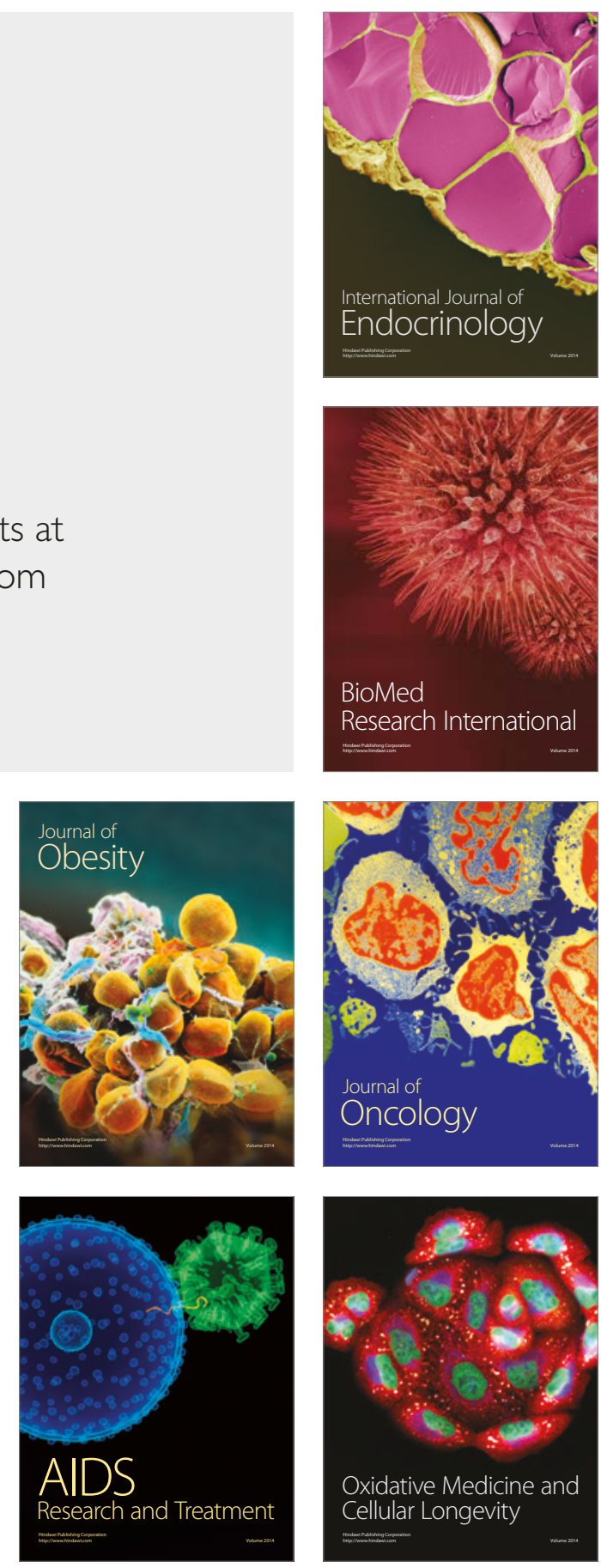